\title{
Green building Design in Public building Design
}

\author{
Saibai Jiang ${ }^{1}$, Chao Sun $^{2}$ \\ ${ }^{1}$ Shandong Urban Construction Vocational College, Jinan Shandong, 250103, China \\ ${ }^{2}$ Shandong Tongyuan Design Group Company Limited, Jinan Shandong, 250014, China
}

Keywords: Public building, Design, Green building.

\begin{abstract}
In recent years' development, economic level in each industry of China has improved but some environmental destruction phenomena emerged. With the improvement of people's life standard, people has set higher requirement for dwelling environment. Under the development of industrial economic development, construction material wastage is getting severer. This article mainly studies green building design in public building design, mainly contents including the major concept, principles to follow and the penetration significance of green concept, so as to promote the overall development of the analysis work and arouse relevant personnel's attention.
\end{abstract}

\section{Introduction}

With the continuous improvement and development of Chinese construction industry, there are huge consumption while continuously improving the economic level, especially in public building. Lack of analysis on building practicability and environmental conservation of building in design work has resulted some defects. Thus construction enterprise development and construction work should be based on environmental protection concept, strengthen the effective development of green technology and promote the formation of environmental conservation. In such condition, it can reduce loss and can satisfy the development demands of green building.

\section{Green building design}

In recent years, green building design concept has been penetrated and become a major concept of people's construction design work. As a new concept produced in construction design, it has penetrated into building design based on respecting natural environment an objective development laws and integrating building design with natural environment. In this kind of development situation, it can save energy resource consumption, promote resource utilization efficiency, and reduce environmental pollution in building construction so as to maintain the environmental conservation of green building which can truly achieve the harmonious development of human, nature, and society. Natural resources on earth are limited. Overuse and consumption of natural resource are getting more and more serious with the continuous development and progress so as to impose great surviving pressure to natural resources. Under such a development trend, environmental degradation will increase gradually if bringing this bad factors into social development. Thus it is very necessary to implement green and energy saving design for maintaining surviving and development of environment. During the period of building design, to change the overall environment, promote its greening and environmental protection, we must introduce advanced design concept and promote the harmony and unity between human and nature. Meanwhile, designers should keep working hard and introduce new type green building design concept to guarantee its effective application and promotion.

\section{Principles to follow in green building design period}

Green design concept application in building design work is of great significance, thus some execution principles should be followed as building has the characteristics of openness and it can establish an organic integrity in the same environment. In design work, to promote the acquirement of 
overall environmental benefits and design based on its integrity. Besides, we should regard efficiency and greening as the key points. The application and development of this concept can reduce energy consumption and use pollution free construction material, but also can promote the hazard-free development of building design. We should also apply it into building design work based on the healthy property and sustainable so as to promote the adaptation of design to achieve the combined application of economy and society. In this way, it can be comprehensively displayed in general. Green building design workflow requires for specific requirement condition and evaluation on its service life during design period. It requires strict construction according to construction drawings, and specific development situation of building so as to promote the effective implementation of green building design. Thus during green building design work, we should think from different aspects and effectively set goals, and guarantee the analysis on the execution principles of green building and the specific framework of its surviving. Under such an execution condition, we can obtain abundant green building theory and can also apply it to the whole development cycle and maintain its sustainable construction.

\section{Comprehensive application principle}

During public building design, to promote its green development, it is necessary to fully introduce green service concept and guarantee that it can provide safe and comfortable life environment. Compared with traditional design concept, green building service concept is greatly different. Application of green construction design is to fully use different resources and energy to promote resource comprehensive utilization and guarantee that the greening can meet relevant requirements. Meanwhile, as there are a lot of personnel circulation in public building design, the expressive form is more obvious, in practical design work, we should make full use of each natural resource based on practical development condition so as to insist "human oriented" development principle in practical work and achieve the harmony and unity between human and nature and guarantee fully penetration of relevant principles during public building design and construction period.

\section{Reasonable benefit principle}

During the practical design period of construction project, it is necessary to analyze the venue, surrounding environment, existing condition and social humanity factors in project engineering construction operation based on the formation demand of green design concept and the practical condition of project. In addition, careful deliberation is required in the work to guarantee that the design can meet requirements, adapt to local economic development condition, and satisfy local enterprise cultural inheritance requirements so as to promote the effective implementation of public building products. It is also necessary to combine operating construction products and market products so as fully display its social benefit, economic efficiency and environmental benefits.

\section{Effective application principle}

In building design work, we need to study the practicability of its existence. But public building green design should promote the formation of humanistic care and achieve the effective communication between interior and exterior building based on the practicability development principle. For example, during design building products, we will use glass walls and need to analyze its existing style, aesthetics and humanistic care effect for reducing light pollution to achieve the effective interaction between human, architecture and the outside world so as to provide good, comfortable and healthy living environment of people's positive development.

\section{Penetration significance of green design in public building design}

Relevant standards established in China have formulated housing and urban and rural construction such as "Green building assessing standard". This standard has summarized green building practical experience in recent years, and obtained good research achievements. Meanwhile, based on national advanced experience, it has formulated several objectives and achieved multi-level green building comprehensive evaluation standard, and promote the formation of green building evaluation system 
according the China's current situation and development requirements. Meanwhile, government and related departments should provide guidance for overall design and promote the improvement public building green design based on thorough and systematic public building green building design evaluation system. Under such a using method, it can provide award for highly greening public buildings and provide effective rectification suggestions for low environmental public building so as to guarantee that they can achieve optimization in a certain range. [1].

\section{Reduce energy consumption}

Green design evaluation in public building can promote energy consumption to be greatly reduced and solve current shortage issue now, and promote the effective formation of public building greening evaluation system. This development trend can satisfy people's demand for material and culture and reduce the energy consumption during construction, and relieve the tense energy supply and demand, and provide effective suggestions for urban positive development and sustainable construction so as to maintain the effective enhancement in economic and construction level.

\section{Improve economic benefits}

The establishment of green design evaluation standard can promote the beneficial obtaining of economic benefits. For some public architecture especially in social development has owned special social functions closely related with each procedures and fields in the society. When evaluating public buildings, we need to take comprehensive thinking. When implementing, we need to think about the economic benefits of project and study the ecological benefits and environmental benefits from different aspects so as to guarantee to select major purpose and implementation scheme suitable for environment development during the analysis process. In such a development condition, it can maintain positive development and smooth implementation of project engineering and promote public buildings to achieve better economic benefits [2].

\section{Studies on green building design in public building design}

\section{Design of exterior building environment}

During the exterior environment of green building, we should take consideration based on environmental greening. Firstly, green building design should be with some innovative thinking and analyze humanities, resource, environment factors in the building for mutual integration and effective resource utilization. For example, analyze based on its integrity and reasonably use each method and way. It is possible to use composite sceneries, borrowed sceneries and divided sceneries to promote the harmoniousness and uniformness of interior and exterior environment. Secondly, analyze the environment greening near the building, reduce hard paving area, increase lawn area and some trees to obtain good greening effect.

\section{Utilization of natural lighting and ventilation}

In natural world, wind energy and luminous energy are renewable resources. During green building design, we should make full use of the natural resources so as to achieve electricity saving and promote the healthy and efficient energy utilization. Analyze from hygiene perspective and we find that sufficient sunlight can develop its bactericidal effect. Thus natural ventilation can remove pollutants indoor and promote the optimization of interior environment and maintain the overall comfort level. Effective combination of natural ventilation and lighting, and application to green building design work can optimize interior environment and can achieve the purpose of energy saving [3].

\section{Design of interior building environment}

When designing building interior environment, we should improve from two aspects. Firstly, design the acousto-optic environment. In green building design, it is possible to use solar energy and other new energy to develop its illumination effect. Application of natural light to indoor is to effective use energy saving lamps and lanterns so as to reduce energy consumption. For acoustic 
environment based design, designers can arrange the bedroom to the opposite direction of noise source and install soundproof window so as to reduce noise and promote comfortability and swap-in. Secondly, design the energy system. In green building ecological environment construction, we should promote energy to be fully used and guarantee that conventional energy system can be improved in design work so as to guarantee the improvement of green ecological energy utilization efficiency. After analyzing based on these points, designers should promote effective implementation of each work such as to promote the effective improvement of construction design level, formulate scientific and reasonable energy improving plan, and jointly apply construction art, resource, and energy. Meanwhile, we should promote the effective utilization of green resources based on the practical regional condition especially the utilization of geothermal resources and solar energy, and wind resources [4].

\section{Application of new type green energy system}

Based on current development status of China's architectural engineering construction, new type energy has been widely used, especially solar energy and wind energy. Due to their utilization features of pollution free and sustainable utilization, they are well received by each architectural design unit. For example, it is possible to collect solar energy, emit heat and apply in people's daily life by using solar-energy conversion device. For wind energy, it can be used for electricity generation to reduce the consumption of electric system. In future development, new energy will be continuously developed and achieve high-efficiency pollution free utilization way [5].

\section{Improvement of building window \& door system}

In architecture, window and door system, and glass curtain wall can maintain structural consumption. With the improvement of modernized technology level, some new products are emerging gradually which have improved the performance of window and door system, and glass curtain wall. Heat remaining property and radiation protection performance of new type and high-performance glass window and glass curtain wall have been used and heir functions have given full play. In addition, effective application of new material and new technology has promoted the improvement of thermal performance and air permeability, and the effective application of architecture and environment. The design of curtain wall involving many functions can realize effective protection function, adjust indoor environment quality and maintain the overall efficacy of architecture.

\section{Conclusion}

In modern economic and social development, implementation of green building can guide people to pay attention to environmental protection, realize the relationship between ecological benefits and economic growth and maintain sustainable construction under severe development situation. Thus public building green design concept can satisfy people's realistic demands for reasonable design, promote energy full utilization, and satisfy current energy saving and environmental demand, so as to promote the ecological and economic development of public buildings.

\section{References}

[1] Yang Wei, Li Can, Li Yi. A small green building design concept and application practice, Building Science, 2014, 30(12), pp.36-42.

[2] Pan Zhihui, Wang Liyun, Li Pei. Case study on a Shenzhen large-scale public building efficient rainwater utilization design, Water Supply and Drainage, 2014, (4), pp.79-82.

[3] Wang Biling, Zou Yu, Wei Zheng. "Analysis on the energy efficiency improvement potential of water chilling unit and its application in "Public building energy saving design standard" (new version), Building Science, 2015, 31(10), pp.52-56. 
[4] Ma Xiaobin. Discussion on the integration of green buildinsg design concept in public building sdesign, Architectural Engineering Technology and Design, 2016, (26), pp.332.

[5] Xie Linlin, Peng Hongpu, Zhao Yue. Studies on the health concept and evaluation of public building, Science \& Technology Progress and Policy, 2011, 28(13), pp.98-101. 